JRIT

15,1

64

Received 11 June 2020

Revised 21 November 2020

Accepted 21 November 2020

\section{"Maddie is online": an educational video cartoon series on digital literacy and resilience for children}

\author{
Konstantina Martzoukou \\ School of Creative and Cultural Business, Robert Gordon University, Aberdeen, UK
}

\begin{abstract}
Purpose - This paper examines children's development of digital literacy, resilience and citizenship in the online environment, addressing active engagement and participation via cartoon videos. Previous research has emphasised the positive role of cartoons in different educational contexts, as important agents of attracting children's attention and interest with opportunities to engage in contextual and collaborative learning.

Design/methodology/approach - The work describes the design and an initial pilot study of the animated cartoon video series, with a group of 30 children in an S1 class, at a secondary school in Scotland as part of workshop addressing digital resilience themes. Children worked individually and in teams in a series of interactive activities, which were evaluated by means of a short questionnaire survey.
\end{abstract}

Findings - The majority of the children enjoyed the cartoon videos which addressed a story of cyberbullying and, in teams, they chose different copying strategies. Children's verbalisations included expressions of positive feelings when connecting online, linked to socialising, creative and playful activities and they expressed a preference towards speaking to their parents and friends rather than their teachers when dealing with online challenges.

Research limitations/implications - Children not only enjoyed watching the cartoon story but had an interest to learn more about how other children deal with the pressures and challenges of the online world, how to manage their own digital footprint and, particularly, how easy it is to spread personal information online. Practical implications - Cartoon animations present an opportunity to act as a basis for encouraging children to exchange ideas and engage in dialogue in class and at home by means of creating a point of reference which creates an environment, where pressure is taken away from the "self". The cartoon character can be the focal point for discussion on issues that may be difficult to address directly and on a personal level because of insecurity or fear.

Social implications - Both teachers and parents have a responsibility to offer support and advice to children and ensure their online safety and resilience. Engaging with children in open further dialogue via fun and interactive cartoon-based activities may help to further explore and understand their perspectives.

Originality/value - The work addresses everyday life issues encountered online and aims to offer educators and parents an engaging and fun series of activities, harnessing the advantages of cartoon video animation as a didactical resource that can utilised as a supplementary learning tool inside the classroom and at home.

Keywords Digital literacy, Digital resilience, Digital citizenship, Online safety, Cartoons, Education Paper type Research paper

\section{Introduction}

There are diverse challenges and opportunities created in the online everyday life context as children (as young as 5 years old) are now using a wide range of social media enabled

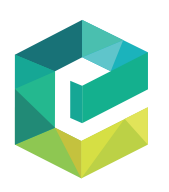

(C) Konstantina Martzoukou. Published in Journal of Research in Innovative Teaching \& Learning. Published by Emerald Publishing Limited. This article is published under the Creative Commons Attribution (CCBY 4.0) licence. Anyone may reproduce, distribute, translate and create derivative works of this article (for both commercial and non-commercial purposes), subject to full attribution to the original publication and authors. The full terms of this licence may be seen at http://creativecommons. org/licences/by/4.0/legalcode

The author would like to thank Plotagon for supporting the project (and particularly Mr Joe Schick) as well as all the individuals who contributed directly to the production of the series, bringing the characters to life with original voice-overs. The author would also like to express her gratitude to School Librarian Mr Ioannis Panayiotakis and to the secondary school in Scotland that agreed to take part in the pilot.
Journal of Research in Innovative Teaching \& Learning Vol. 15 No. 1,2022 pp. $64-82$ Emerald Publishing Limited 2397-7604 DOI 10.1108/JRIT-06-2020-0031 
online tools for messaging, video sharing and online gaming to connect with others, learn and experiment. Research with school children demonstrates that, although they have grown up with the online environment, they still require support to develop digital competences. For example, McGrew et al. (2018), focusing on the issue of "civic online reasoning", in a study of young people (from middle school, high school and college), found that approximately 80 per cent lacked "the ability to judge the credibility of information", expressing worry that the spread of disinformation may be pausing a threat to democracy (McGrew et al., 2018, pp. 4-5). A study by Picton and Teravainen (2017) found that 1 child in 5 lacked basic critical skills required to deal with misinformation via social media, believing that everything they read online is true. The final report from the Commission on Fake News and the Teaching of Critical Literacy Skills in UK Schools (National Literacy Trust, 2018), concluded that only $2 \%$ of children and young people have the critical literacy skills they need to tell if a news story is real or fake. It also revealed that almost two-thirds of teachers believe fake news is harming children's well-being by increasing levels of anxiety, damaging their self-esteem and skewing their worldview. Half of teachers felt that the national curriculum does not equip children with the literacy skills they need to identify fake news, and a third expressed that the critical literacy skills taught in schools are not transferable to the real world. This phenomenon was described as threatening children and young people's, "wellbeing, trust in journalism and democracy itself". At the same time, children are most likely to talk to their family $(29.9 \%)$ and friends $(23.4 \%)$ about fake news and least likely to speak to their teachers $(6.4 \%)$ (National Literacy Trust, 2018, p. 4). In addition, latest research with young children in the UK by Ofcom (2019) suggests that "three in ten users aged 8-11 and 12-15 believe that if a website is listed by a search engine it can be trusted" and "only a minority of $8-15$ s who use search engines $(23 \%$ for $8-11$ s and $33 \%$ for 12-15s) correctly identify sponsored links on Google as advertising" (a phenomenon that has remained unchanged in the last few years). Recent research on children's news consumption and attitudes in response to COVID-19 related information has found that for half of $12-15$-year-old children $(52 \%)$ it is "hard to know what is true and what is false about Coronavirus", while a quarter (24\%) agree that they are "confused about what I should be doing in response to Coronavirus" (Ofcom, 2020, p. 2)

In addition, while connecting, playing and socialising with others online, children experience a number of challenges, such as cyberbullying and social pressure to be popular all the time. Children feel the need to be constantly connected online with almost half ( $45 \%)$ of 11-18-year-olds admitting checking their mobile device after going to bed (Salmons, 2016). One in ten $12-15$ s have "gone live" by sharing a video using live streaming services such as Facebook Live, Snapchat's Live Stories or Instagram Live while they also adopt new ways of interacting, e.g. sending messages every day over consecutive days and diversifying their online media use (e.g. TikTok and Twitch are becoming popular tools) (Ofcom, 2019).

Mobile Applications, such as TikTok and Snapchat, are used by children to socialise, play and be creative, posting images, videos, and information about themselves as well as posting comments, and interacting with others. However, many parents worry that the same tools and applications may become addictive, replacing the valuable face-to-face social interactions with peers and distracting children from spending time with the family or engaging in other hobbies and creative activities. In addition, as children use new and constantly changing social media apps, often following a "more is better" approach (e.g. seeking more likes, followers, and time spent on social media), parents cannot easily keep up with the minimum age requirements, the safety features available or with the digital wellbeing challenges that children may be encountering. An enquiry report by Young Minds and the Children's Society based on data from a survey of 1,089 young people aged 11-25 conducted in the UK in 2017, found that the use of social media by children younger than the age of 12 is commonplace, with $61 \%$ of young people creating their first account at age 12 or under, although the most
An educational video cartoon series 
JRIT

15,1

\section{6}

popular social media tools - including Snapchat, YouTube, TikTok and Instagram clearly indicate that they are aimed at children of 13 years old and above (The Children's Society and Young Minds, 2018b). In the UK "Online Harms" is a key legislative priority for the UK government, to tackle the issue of younger children accessing inappropriate content, calling social media companies for age appropriate content and technologies that will protect children (Department for Digital, Culture, Media and Sport, 2020).

As it is clear from the above issues, more emphasis is required on keeping the communication between parents and children open on the basis of both the challenges and the opportunities of online connectivity in the home environment as well as the development of a digital literacy and resilience mindset early in education. Resilience "is the ability to deal with negative experiences online or offline. Resilient children are able to tackle adverse situations in a problem-focused way, and to transfer negative emotions into positive (or neutral) feelings" (d'Haenens, 2013, p. 2). As Reynolds and Scott (2016) put it, this will help children to become "active and informed in their citizenry online - more likely to intervene positively in negative situations online, more likely to consume online information critically, more likely to engage positively in online social and political discussions, and to understand the dynamics of social media and how they change our communications" (p. 19). This has also been described by the Council of Europe, as "digital citizenship", "the capacity to participate actively, continuously and responsibly in communities (local, national, global, online and offline) at all levels (political, economic, social, cultural and intercultural)" (Council of Europe, 2019, para. 4).

In recent years, there is a focus on children's development of digital skills for the online environment, addressing not only safety and protection but also active engagement, participation and learning in the digital society. With this comes an emphasis on empowering young people with skills that help them to deal with the challenges and dangers of the online world but also understand wider online social issues and phenomena in their digital lives, such as cyberbullying, online privacy, online ethics, online democratic participation and human rights. Educators are called to support, guide and enable young people "to participate safely, effectively, critically and responsibly in a world filled with social media and digital technologies", and develop "a range of competences, attributes and behaviours that harness the benefits and opportunities the online world affords while building resilience to potential harms" (Council of Europe (2020). In addition, "digital resilience" is presented as "a dynamic personality asset" which focuses on digital activation and engagement with both opportunities and challenges as opposed to passive and avoidance behaviour (UK Council for Internet Safety, 2020, p. 4).

In order to actively engage the interest of young children in digital literacy and digital citizenship issues, a range of different educational material are available which emphasise the active role of parents and educators. For example, Internet Matters (https://www. internetmatters.org) offers access to safety checklists for children of different ages, guides on how to set parental controls on a range of devices, and practical tips; ParentPort (http:// www.parentport.org.uk/top-tips-for-parents/) offers tips for parents for keeping their children safe offering different sources to tackle issues related to online safety, mobile safety, social networking, advertising and video gaming. Digizen (http:/www.digizen.org/ parents/) provides information on social networking and cyberbullying; Young Minds offer resources and advice for parents and carers on how to help their children Stay digitally resilient (https://youngminds.org.uk/); Childnet (www.childnet.com/parents-and-carers) offers resources that can used by families to discuss issues related to young people's connectivity and The UK Safer Internet Centre (https://www.saferinternet.org.uk/) offers online safety advice for parents and carers. Other organisations and charities offer a range of resources on digital citizenship, literacy and resilience, such as WIZE Kids (https://wisekids. org.uk/wk/parents-foster-carers/\#) as well as parent guides to apps, games and social media 
sites, such as Parentzone (parentzone.org.uk/advice/parent-guides), the NSPCC s advice on how to keep children safe on their favourite websites (https://www.net-aware.org.uk/), Internet Matters (www.internetmatters.org/parental-controls/), National Online Safety (nationalonlinesafety.com/guides), PEGI Game Age ratings (/www.pegi.info), Common Sense Media (https://www.commonsensemedia.org/app-reviews) and Ask About Games (www.askaboutgames.com/).

The above are just a few examples of Projects, out of many, that highlight enquiry-based learning approaches which aim to engage both children and their parents or educators and prepare them to address challenges encountered when dealing with the online environment. However, there are only a few examples of educational videos which deal with real life online issues, aimed directly at children, such as "Let's Fight It Together" cyberbullying video from Childnet (https://youtu.be/VAhq_dxRjcI), or cartoon stories which tackle Internet safety issues such as the "BBC Newsround Internet Safety Film" (https://youtu.be/kgCNGvL0g1g) and "Josh and Sue" by The UK Child Exploitation and Online Protection Center (https://youtu. be/XQsylepmE90). These are not used as tools for just entertainment but as a way to engage children directly with real-life online issues they may be experiencing and relate to their own circumstances.

Online resources have become even more important within the context of a post COVID-19 educational environment, where remote learning presents a normal new reality for children and teachers across different educational settings as well as families. Not only teaching, learning and information dissemination approaches have fundamentally changed, with the almost exclusive provision of online teaching and learning, but there is now also an increasing demand amongst schools to have a more active online presence, which may signal a more open attitude to experimentation with new methods of online teaching and delivery. Within that new era, interesting multimedia resources and engaging teaching material, which relate to children's everyday life online experiences, are more important than ever for maintaining the interest of students and offering interactive and interesting learning experiences.

\section{The value of cartoons as educational resources}

Previous research has emphasised the positive role of cartoons in different educational contexts, as important agents of attracting children's attention and interest with opportunities to engage in contextual and collaborative learning (Wyk and Micheal, 2011). Using cartoon storylines is an authentic pedagogical tool that can be used for diverse educational purposes, and as a method for attracting the attention of young people, stimulating critical thinking and discussion. The use of cartoons offers a pedagogical advantage by means of allowing visual and auditory stimulants which can help to convey in an interesting manner key concepts, behaviours and practices within the sociocultural context they take place. For example, Özer and Avc1 (2015), observe that cartoons “. . . as important agents of cultural transmission, are instructive domains which present informative materials for children" (p. 419) and can help children to explore concepts of "family", "culture", "community" and lifestyle. Cartoons have been generally found to be "powerful pedagogical tools" in education "combining audio messages with tailored visual cues and graphics, to serve the dual functions of explaining complex concepts and engaging student interest in the learning process" (Liu and Elms (2019). Dalacosta et al. (2009) explored the effectiveness of animated cartoons in teaching at schools and found that they were effective in transmitting scientific concepts to fifthgrade students offering opportunities for visual cues and emphasis on particular aspects of the subject taught. The animation movies expanded students' knowledge and comprehension and they were well received by most young people. Studies with school 
JRIT

15,1

children have also explored how cartoons can allow children to engage with an imaginary world via fictional characters by freely visualising themselves as members of that reality, as a window to a real world which helps them to understand phenomena, shaping their real-world values (Türkmen, 2012).

\section{"Maddie is online"}

In response to the above educational opportunities and benefits presented by cartoons, this paper describes the design and initial evaluation of an animated cartoon instructional video series, "Maddie is Online". "Maddie is Online" is aimed at young children aged 9-12-year-old and can be used as a means of engaging them critically with digital literacy, digital resilience and digital citizenship principles which have emerged as key concepts in both academic research and government policy agendas. That direction highlights the need to focus not only on the technical skills required in today's digital online environment but also on important aspects of digital literacy such the ability to find, understand, use and share information as well as the ability to create media and communications in diverse online contexts, following responsible and ethical behaviour. The series, therefore, addresses everyday life issues encountered online and aims to offer educators and parents an engaging and fun variety of activities, harnessing the advantages of cartoon video animation as a didactical resource that can utilised as a supplementary learning tool inside the classroom and at home.

"Maddie is Online" has been presented at the Librarians Information Literacy Conference (LILAC) (Martzoukou, 2019) and as an invited presentation by the Information Literacy Group (ILG), a special interest group of the Chartered Institute of Library and Information Professionals (CILIP), and as part of the UNESCO Media and Literacy (MIL) week celebration (Martzoukou and Geekie, 2019). The series has its own blog space available (https:// maddiesonline.blogspot.com)/) which offers direct access to the video material together with instructions and ideas that complement it. The activities featured on the blog can become the basis of school training sessions together with additional reflective and evaluative exercises. Participants are also be invited to express their thoughts and feelings related to the online world by means of sharing ideas via@MaddiesOnline Twitter account. For example, the series has been used with university library and information science students as a means of encouraging them to critically reflect on the issues addressed and considering how future school librarians can play an active role in supporting young children to develop important skills for the digital age. Different ideas and reactions to the scenarios of the series can be found via the Twitter account's postings.

"Maddie is Online" offers an accessible cartoon animation education resource for school teachers, school librarians and parents, focusing on digital citizenship skills young children require to navigate and evaluate their digital environments effectively by means of extending the reach and relevance of young learners' opportunities to develop information and digital literacy in ways which relate to their everyday life online interactions. It draws attention to the younger online media and information users and provides a tool that can be used with preteen children. It can be incorporated into subjects to create engaging and creative learning resources for children in both primary and secondary schools and has been designed on the basis of the concept that in order to engage younger children in these issues, it is important to offer learning opportunities which are interesting and relate to their own everyday life online experiences.

The animation videos were created using Plotagon Studio (Plate 1) which is a commercial, animation tool that allows to create customized characters with voice-over functionality. The software enables the integration of step-by-step scripts in different scenes and allows to link them with character expressions. There is an array of available scenes (e.g. a school class, a street view, different house rooms, a library, a restaurant, a café) and characters to choose 


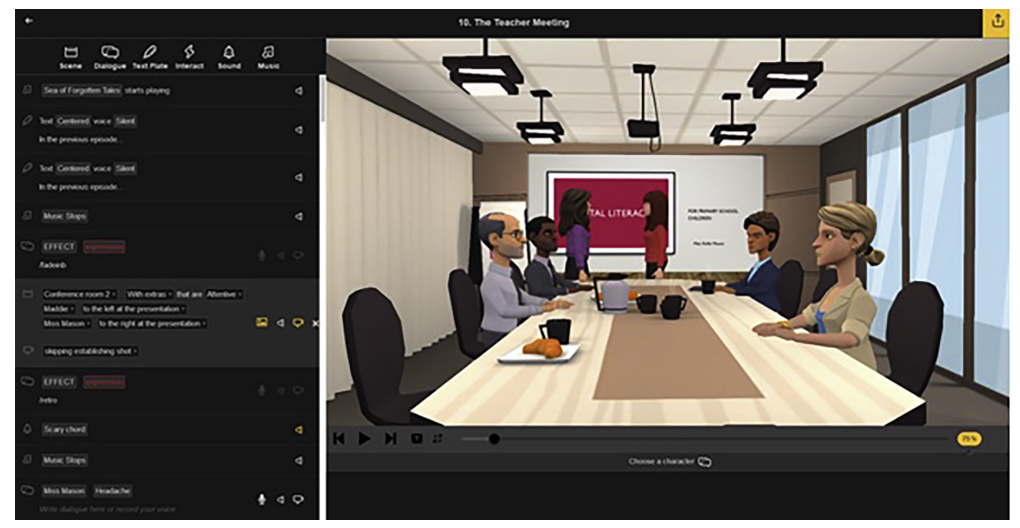

An educational video cartoon series

Plate 1. Plotagon Studio Script Interface from 'Maddie is Online' Series 2

from which can be customized and placed in dialogue with each other, although with limited interactivity between them (e.g. handshake, tease, pat). However, there is a good offer of different expressions which relate to moods and emotions (e.g. happy, agreeing, relieved, proud, afraid, sceptical bored, ashamed, ironic, sad) and sound effects to choose from (e.g. cell phone ringing, alarm, crowd whispering, computer keyboard) which can help to create a realistic scenario. With the addition of other sound (e.g. surprise and mood related sounds, music) and visual effects (e.g. black and white and sepia colour lines) and scene transitions, a believable storyline, can be created using elements of both reality and fantasy.

Videos can be exported in MP4 video format and uploaded to online video platforms such as YouTube and Vimeo. A number of case studies of institutions that have used the software for educational purposes are featured on the company's website and include, among others, the Berlin School of Economics and Law, Western Sydney University and the Ruppin Academic Center in Israel (Plotagon, 2019).

"Maddie is Online" was created with real voice actors (Plate 2), involving both children and adult voices, in an effort to create a more realistic and believable story, although the tool also

VOICE-OVERS

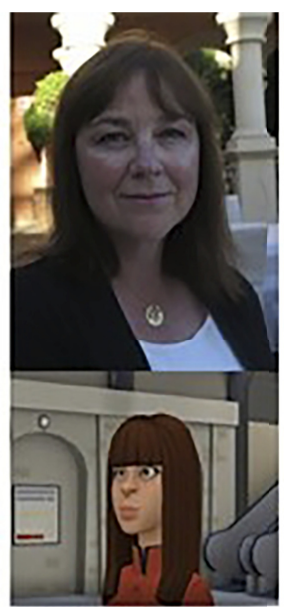

Miss Mason - Professor Adrienne Muir

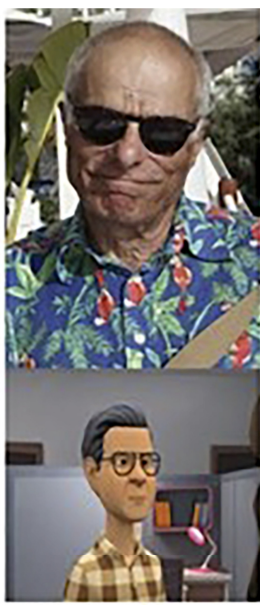

Andy, The Bold Voice Professor Charles Oppenheim
Plate 2. Voice-over Actors 
JRIT 15,1

offers the option of digitised voices that could be added instead. A total of thirteen different voices were used in the series including the voices of three children.

The series currently features two storylines which address different elements of the digital society, involving the central character, Maddie, a preteen girl interacting with a range of characters which represent her friends, her teachers, and other people she encounters in her everyday life.

\section{"Maddie is online" series 1 . Online resilience}

Series 1. Online Resilience (Plate 3) deals with issues of online resilience on social media and it consists of eight episodes which last approximately seventeen minutes. The series also includes an extra episode on "Reflections on social media and cyberbullying" (which lasts just above four minutes). In the story, cyberbullying is approached on the basis of sending in the form of cruel and unsensitive comments via Internet social media websites. However, cyberbullying "may occur on personal websites or it may be transmitted via e-mail, social networking sites, chat rooms, message boards, instant messaging, or cell phones" (Feinberg and Robey, 2010).

A written scenario is provided via the cartoon blog aimed at teachers or parents who wish to utilise the videos, which explains Maddie's daily routine and tools she uses online at home and at school. Maddie is presented in the story as a young pre-teen girl, whose morning begins with greeting her friends on iPhone "messages" as she gets ready for school. Maddie has an iPhone 5 and a tablet where she uses many different applications: FaceTime, Snap Chat, Pinterest, Instagram and TikTok, an App you can use to lip-sync to music and share videos of yourself. Maddie has her own Bitmoji and she regularly uses YouTube, Google photos, Gmail and Skype and she plays Roblox fanatically. At school, she uses an app called SumDog, which is a maths game you can join with players around the world. Maddie's phone is not just a tool she uses, it is a facet of her "self". It is part of who she is - part of what makes her human in a growing interconnected online world. By extension, her knowledge and her network of friends online is also interwoven into her sense of self, it is an element of her identity. Although this is her techno self, it is also her real self in many ways.

However, Maddie's online troubles begin when she experiences being cyberbullied, when another girl, called Jasmine, she has not met before, makes fun of her lip-syncing video she posted online on a social media app. Not knowing what to do, Maddie turns to the audience to ask for help and invites them to choose the best solution for her.

Plate 3.

Introductory Episode Series 1

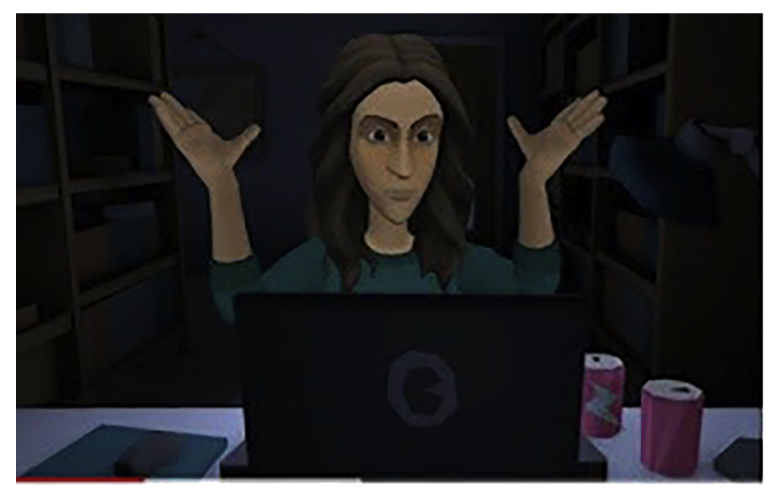

Maddie is Online - Introduction 
Children are given instructions to watch carefully the first video ("Maddie is Online Introduction"), which introduces the scenario. The children are then placed into teams (of three to five people) and are given six different options to choose from. Each team is asked to choose one option and explain the reason they chose it. The options range from ignoring/ confronting the situation, to speaking about it, and to giving away her phone.

\section{"Maddie is online" series 2. Misinformation}

Series 2. Misinformation consists of eleven longer episodes and aims to highlight the importance of information seeking and evaluation on the internet. The story, which is a combination of reality and fantasy, begins with Maddie discussing with her friend a school assignment, which involves searching for information on an unfamiliar country for a class presentation. In her quest to find good quality information, Maddie asks many different people for information, including the computer class Pupil Support Assistant, who has just started her new role at the school, a travel agent, a scientist, a librarian, a teenager and a journalist (Plate 4). Maddie finds out some interesting and useful facts about the country but also some controversial and confusing information. For example, in episode 7, "The Bold Voice" which deals with critical information evaluation, Maddie meets Andy, a journalist who distorts the truth by giving emphasis only on one perspective. Andy describes a story about an island where a number of wind turbines were installed and the inhabitants of the island were not happy. However, Andy presents only one side of the truth and also distorts the real facts to depict a story that presents wind turbines destroying the coastal scenery and becoming a threat to wild animals. As this story unfolds, children who watch the series can engage in a research activities to explore both the positive and negative aspects of wind turbines as well as other fake news stories, which demonstrate how truth can be manipulated and changed to suit an audience (for example, another belief Andy promotes is the weight loss properties of chocolate).

The story ends with the importance of evaluation criteria such as currency, authority, point of view, and highlights the "How to spot fake news" infographic, developed by the International Federation of Library Associations and Institutions (IFLA, 2020) which helps to understand different evaluation criteria. A range of activities to engage children critically with issues of information seeking, critical evaluation and misinformation on the internet are incorporated in the series. Information evaluation criteria are reiterated during "The Teacher Meeting" episode where Maddie explains what happened in the story and addresses information currency, relevance, authority, accuracy and purpose. Children who watch the story are asked critical evaluation questions, such as "What did you think of this story?" and "What would you do if you were in Maddie's place?"

The value of the "Maddie is Online" series lies with the flexibility and accessibility of the resources on the basis of utilising them in different lesson plans to engage children in critical discussion about issues that matter to them. Emphasis in this project is placed on recognizing the multiple challenges young people encounter when navigating their online environments with the propose of finding good quality information and dealing with issues such as misinformation, fake news and the ethical sharing of information. Within that domain,
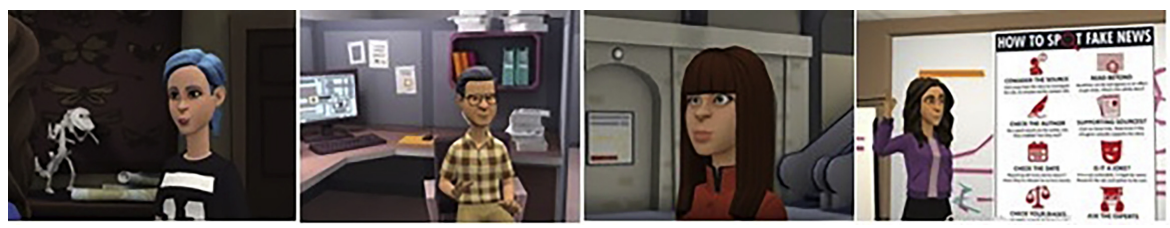

An educational video cartoon series 
JRIT

15,1

teachers, parents and librarians can play an important role in providing a positive presence and supportive culture between home and school, creating a space for online positive, fun and creative activities that can help children to learn how to handle online sensitive issues, how to share information online, how to protect their digital footprint and how to take opportunities for positive and ethical online interactions, playing a pivotal role in developing a positive online digital citizenship culture for young people.

In addition "Maddie is Online" encompasses not only the dos and the don'ts of online behaviour but an understanding of the emotional dimensions of online connectivity (e.g. digital likes, connections, challenges) and how it influences mental wellbeing, helping children to engage in discussion on ways to safeguard their digital footprint (e.g. what they share, how, where and with whom) and ways to be smart about the websites they visit, and the people they engage while being connected online.

\section{Pilot study}

In order to establish the usefulness and relevance of the series, it was important to critically evaluate its outcome with young people, by means of running the videos and collecting anonymous data. For this purpose, "Maddie is Online" Series 1 was piloted and evaluated with an initial group of 30 children in an S1 class, at a secondary school in Scotland. The evaluation took place in March 2020 with the assistance of the school librarian and a school teacher, as part of a wider workshop delivered inside the school library. The workshop addressed digital resilience themes, such as the use of mobile phones, screen time, feelings in the online environment, online resilience, digital footprint, and digital cookies and spiders. The workshop lasted approximately an hour.

\section{Ethical procedure}

Written permission was obtained from the school to collect and publish anonymously the data of this pilot study. To ensure the privacy and anonymity of the children, who took part in the pilot study, no names or any other personal data were recorded in the questionnaires beyond their gender and age. An "Ethics and Contributor Consent Form" was sent to the school explaining the purpose of the series, the background and the value of the project, what the activities would involve and how data would be published. The form also explained that the anonymity of the children would be protected and that any personal data would be removed. It further addressed the low-level risks associated with participation in the project, ensuring that the activities would not be connected to any forms of assessment or influence the academic performance of the students and that participants could withdraw from the study at any point if they required to do so. The study subscribed to the ethical conduct of research and to the protection, at all times, of the interest, comfort, and safety of participants.

\section{Ice-breaking activities}

A number of initial ice-breaking interactive exercises were designed prior to playing the video according to the themes of the workshop. These included a "warming-up" activity which aimed to explore children's connectivity experiences, asking them about mobile phone ownership and using online games and social media apps, such as Snapchat, TikTok, Instagram and Roblox. This was followed by an online communication game which got the children to explore their own and the teacher's knowledge of online communication acronyms (e.g. BRB - Be right back, AFK - Away from keyboard, BAK - Back at keyboard) to highlight the differences between children and adults as well as the worries of parents. A third game in the workshop asked children to express in clouds and stars their feelings (both positive and 
negative) when engaging with online activities such as online playing, online socialising and creating online with digital tools (Figure 1).

The ice-breaking activities offered some initial understanding of children's online experiences and media use and encouraged the children to open up and share their knowledge, understanding, thoughts and feelings. For example, although these were not meant to be studied systematically, it was found that all children had their own mobile phones (except for one child who also expressed that they were not using the internet at home and found it difficult to participate on the same level as others), they had mixed levels of knowledge around online communication acronyms (possibly signifying diverse levels of exposure to texting on apps and social media) and had a range of different emotions connected to the online activities they engaged with. Interestingly, "being online" had a diverse meaning for children, with some of them answering the question with reference to online gaming and entertainment activities and with others referring to creating things online (e.g. art), learning, communicating socialising, and connecting with friends. As the following children's verbalizations demonstrate, most of the replies included expressions of positive feelings when connecting online. For example, several children expressed a feeling of happiness: "I feel happy and free online because there are no adults to bug me" and "I feel happy and entertained as I use it to do homework and it helps. I'm sociable too". Children also felt happy because they were "involved", because they felt "appreciated" and were able to share their creative works with others online and "get great feedback". Other children emphasised the sociable character of their online interactions and the affordances of the online environment for connectivity. As they explained: "I feel enjoyed because I get to communicate with my friends even if they are however far and I get to play very good games online" or "I felt fun and I could chat with my friends" and "Sociable because I got to talk to friends I haven't seen in a long time". A couple of children referred to feeling "appreciated" while being part of a team playing online and enjoying the same game and "valued" when others interacted and engaged in dialogue with them. Other children stressed multiple positive feelings created by activities online, such as being creative, popular, involved, excited, appreciated, smart, alive, excited and knowledgeable, e.g. watching YouTube videos and learning new things they liked.

However, several children also expressed mixed feelings. For example, a child referred to feeling insecurity "because a lot of people make me feel uncomfortable and teasing me
An educational video cartoon series

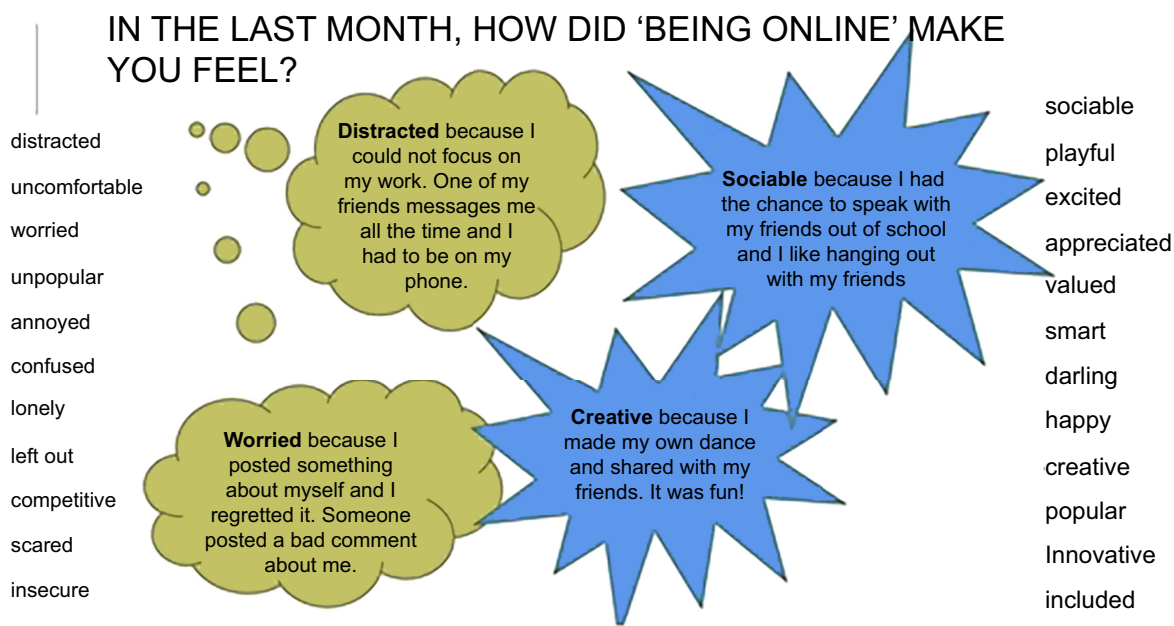

Figure 1. Clouds and stars ice-breaking game 
JRIT

15,1

by telling me all my flaws" which was replaced in other occasions by feeling "valued, when I post pictures of my art". Sometimes children felt happy, smart, creative, excited, sociable, daring and popular (especially when they received likes and popularity snaps) whereas other times they felt distracted, left out, and worried. For example, activities that allowed them to speak to their friends made them feel creative and sociable whereas sometimes they felt "unpopular and left out" when they saw friends online interacting without them.

Only three children expressed exclusively negative feelings. For example, one participant mentioned again how being online "makes me feel left out when people leave me out of things and don't talk to me", while the other two mentioned being "Distracted - because when I'm doing my homework and I get a message from my friend and then I leave my homework and reply" and getting worried "if you said something and you can't get it back".

\section{"Maddie is Online" cartoon video}

The ice-breaking activities were followed by a team-based exercise which involved the "Maddie is Online" video series 1. Children were first asked to watch the initial introductory video, which was played in class, introducing them to the scenario and the protagonist of the story, Maddie, and then they were placed in teams of five. Each team discussed the available choices and decided on the scenarios that presented the best solutions. There were a total of six possible solutions and the children were provided with ten tokens to place on the scenarios they mostly preferred. The emphasis was on distributing their tokens according to the strength of the solution and explain in their team why they placed the tokens in that way. The possible scenarios were as following:

(1) Ignore the message

(2) Confront the child

(3) Go to mum and ask her what to do

(4) Give the phone to mum

(5) Go to mum and ask her to speak to the child

(6) Unfriend and block the child.

They were designed on the basis of previous work developed by d'Haenens et al. (2013), distinguishing three different categories of coping strategies, understood as "thoughts and behaviours to adapt to stressful or disturbing situations, in order to protect oneself from further psychological harm": (1) "fatalistic/passive coping strategies", which involve decisions that relate to not using the Internet for some time or taking no action and expecting the problem to disappear on its own, (2) "communicative coping" which involves talking to someone else and (3) "proactive coping" with options such as "trying to fix the problem" and "deleting unwelcome messages" (p. 2).

Children in their teams chose different solutions, demonstrating diverse levels of engagement with the problem and willingness to take direct action or involve others to help. For example, two of the teams chose to confront the child directly, one of which wrote: "I would confront the child to respectfully ask her to stop. If she continues then report her account and block her from the page". Another team gave priority to asking for help to start with before blocking the child: "I think No.3 because an adult is mature and would know the best thing to do. Or No.6 because then she won't get comments from the girl as well”.

Overall, however, most teams chose the option of unfriending and blocking the child. Various different explanations were given as follows: "I think that she should unfriend 
Jasmine because then she can't put any bad comments on her videos, so she should also block so she cannot friend her back" and "So they can't do it again and it is not too serious". Another team explained that they would choose this option "Because she is cyberbullying", while another one said: "It is reasonable and makes sense".

It was interesting to find that the results of this small-scale study, agreed with previous research in this area. For example, in an earlier survey conducted by d'Haenens et al. (2013) as part of the EU Kids Online project, it was found that when dealing with issues of online bullying, the majority of children would block the sender and this was evaluated as the most helpful strategy which was described as a "proactive coping (problem-solving)" explained above (p. 2).

At the end of the session, videos with the different choices were played so that the children could explore what happened in the different scenarios. Intentionally, none of the scenarios were made in a way that was linked to a correct solution, as in each, Maddie would come up with new questions and problems to explore. This was explained to the children on the basis that not all situations may be similar and therefore, a combination of different methods or even other methods may work better. The story was concluded by means of playing the last video, "Maddie is Online Final Thoughts", which explained the "moral" of the story and offered advice on what would be helpful to do in similar situations.

\section{Workshop evaluation questionnaire}

After the end of the workshop, the participants were asked to indicate which part of the workshop they enjoyed most on the basis of a five-point Likert scale (i.e. ranging from "I did not enjoy it at all" to "I enjoyed it very much"). In addition, the children were asked if they would like to have additional similar activities in the future organised in their school and they were given a choice of topics covered in the workshop they would like to explore more. The topics included facts about other children and what they are doing online (e.g. how many have phones, how many take phones to bed, their worries etc.), information on digital footprint, such as how easy it is to spread personal information and ways to protect personal information online, parents' worries, digital cookies and how they work, the law that protects children online, as well as an option to have more "Maddie is Online" videos to discuss.

Finally, to link to the theme of "Maddie is Online" series 1 , and encourage children to reflect on the activity on a personal level, they were asked to indicate whom they would normally talk to if they had worries about the online environment, choosing one or more of the following options: your parents/guardians, your friends, your brother or sister, your teacher, nobody or any other people you would like to mention.

\section{Results}

A total of 24 children (out of the 30 who participated in the session) returned the evaluation questionnaire. The majority of the children were male $(n=14)$ and 12 years old $(n=21)$. The remaining students were female $(n=8)$, non-binary $(n=1)$ and gender fluent $(n=1)$. Most of the participants were 12 years old $(n=21)$, while there were two students who were 13 years old and one who was 11.

\section{Evaluation of workshop, favourite activities and future topic preferences}

Half of the students "enjoyed" the session $(n=15)$ while the remaining "enjoyed it very much" $(n=8)$ and only one participant said that they "did not enjoyed it very much". Out of all the workshop activities, the preferred one was the "Maddie is Online" videos $(n=20)$. In open comments children explained that they enjoyed the series for different reasons: "I liked 
JRIT 15,1

\section{6}

Table 1.

Topic preferences for future activities watching the videos of Maddie because they were real life scenarios", "I liked the choice of different scenarios in a situation", "I got to see how someone else deals with stress", "I liked watching the videos by Maddie and how she related to her problems", and "I liked own opinion". Three children only chose other themes/activities addressed in the workshop, e.g. "dealing with how adults may deal with "screen time", that they "got to know what some stuff mean" (e.g. digital cookies for example) and "learning about online safety". One child did not give a relevant answer.

In addition, the majority of the children $(n=19)$ answered positively to the question "Would you like to have more activities, like this one today, at your school?". Only one student gave a negative answer and the remaining were not sure $(n=4)$.

\section{Topic preferences in relation to similar future activities}

Participants were asked to choose from a number of options (Table 1) in relation to topics they would like to know more, reflecting the topics that were covered in the workshop. The data demonstrate that children were mostly interested in finding more about their "Digital footprint. How easy it is to spread personal information" $(n=19)$, followed by the "Maddie is Online" videos which presented the digital resilience topic of the workshop. One participant who chose the "other" option explained that they would like to "Talk more about how people are bullied online for their sexuality and/or gender".

In addition, participants were asked to indicate the person or persons they would speak to if they experienced problems online. "My parents/guardians" $(n=21)$ was the most popular option, followed by "friends" ( $n=10)$ and siblings $(n=8)$. Interestingly, only a small number of children $(n=5)$ chose "my teacher" as an option (see Table 2).

Parents have a responsibility to offer support and advice to children and ensure their online safety and resilience. However, a recent UK government consultation with key stakeholders on the issue of online harms found that although parents felt that are best placed

What topic would you like to know more on? (Tick all that apply) N

Facts about other children and what they are doing online (e.g. how many have phones, how many take 9 phones to bed, their worries etc.)

Digital footprint. How easy it is to spread personal information

Digital footprint. Ways to protect my personal information online

Parents' worries

Cookies (not real ones, digital)

More about the law that protects children online

"Maddie is Online" videos

Nothing. I knew everything already

I was not listening but I promise I will next time!

Other 9

6
Table 2.

Choice of people to speak to when experiencing online problems
Whom would you talk to if you had worries about the online environment?

My parents/guardians

My friends

My brother or sister

My teacher

Nobody

Other 
to tailor advice for their children they also agreed that there is need for additional "advice and education on how to be online safely". Online safety was considered by parents as a low confidence area with a need to increase education for both them and their children (Department for Digital, Culture, Media and Sport, 2020). Although children in this study appeared to be less open to approaching their teachers, it is important to also ensure that digital literacy education is incorporated into their curriculum of both primary and secondary schools, which may encourage more children to open up and speak to their teachers about these issues. This is particularly important as not only children are increasingly connected online at a younger age but recent surveys also demonstrate that more children experience online harms. For example, The Children's Society and Young Minds (2018a) in a study of online bullying and abuse, found that above half of respondents $(55 \%)$ had experienced incidents online which left them feeling upset, angry, anxious and insecure; despite that over a third would not speak to anyone about their problems. In addition, only $19 \%$ of parents when asked believed their child had suffered online bullying or abuse and almost all teachers in the study relied on children to alert them about these issues, feeling unprepared to deal with cyberbullying issues, while, at the same time, only $5 \%$ of pupils said they would discuss their problem with a teacher.

\section{Discussion and conclusion}

"Maddie is Online" has been designed with awareness of the importance of learning from the environment and how it influences children's behaviour by means of imitation. Bandura's social learning theory discusses the impact of influential models on children (i.e. the people surrounding them in their immediate social environment, such as parents and close relatives, older siblings, teachers, friends). Bandura refers to the process of "vicarious reinforcement". Children learn by means of observing not only specific behaviour but also the consequences of that behaviour. For example, if a particular behaviour is awarded or praised this may mean it is more likely for children to imitate it (Bandura, 1971).

Cartoon characters, who simulate incidents that happen in the real world in a believable story, and who may look, behave and act in a way children can relate to, can, similarly, become models of behaviour. On this basis, children can learn via observational learning and imitation, watching cartoon characters who resemble them. These characters can grab their attention if they have similar characteristics with them (e.g. if they are in a similar age), if they have a particular quality they would like to possess, if they experience similar challenges as them, if they act within a familiar environment to them (e.g. in a school) and if they have similar points of reference (e.g. playing a popular online game or using an app). In other words, children can identify with not only the character, but also relate to their circumstances, and closely observe situations experienced, difficulties encountered, values, beliefs and attitudes developed, as well as reactions and decisions made within a familiar context they recognise; this allows them to notice, consider and reflect upon aspects of behaviour they relate to and decide which ones to take on or adopt.

Cartoon video stories can also help children to form a mental picture of the story, its values and morals in a memorable way, helping retention. Children can revisit the story, watch it together with others and discuss it critically. This can then reinforce their motivation to accept and follow particular behavioural models.

This is particularly important in the case of "Maddie is Online" cartoon story, the full potential of which could be realised not simply by watching the videos but by means of engaging in the dialogic learning activities that have been designed around the scenarios and other additional activities/opportunities for discussion that teachers, librarians and 
JRIT

15,1

parents may wish to further develop to explore some of the behaviours, values and mindsets presented in the videos. Spending time for meaningful dialogue in class, at home, with teachers, parents and friends is important for advancing learning and understanding of the issues the series addresses, help the children to relate those to their own problems and circumstances, find how others deal with them and stimulate their critical thinking.

Although the preliminary evaluation of Series 1, presented in this paper, was conducted with a small number of participants (there are currently further plans to engage additional schools with both of the series' episodes), the children not only enjoyed watching the cartoon stories but had an interest to learn more about how other children deal with the pressures and challenges of the online world, how to manage their own digital footprint and, particularly, how easy it is to spread online personal information. Some of the children also expressed interest to know more about their parents' perspectives and worries. In addition, it was interesting to observe that children would talk about these issues more with their parents and friends but less with their siblings and their teachers. "Maddie is Online" therefore may present an opportunity to act as a basis for encouraging children to exchange in dialogue in class and at home by means of creating a point of reference which creates an environment, where pressure is taken away from the "self", making the cartoon character as the focal point for discussion on issues that may be difficult to address directly and on a personal level because of insecurity or fear. Children may also wish to create their own cartoon characters to express their feelings and experiences in a less challenging way.

It is important to note that the importance of engaging in activities which get students to critically discuss these issues at school and in the home is not always clear. For example, in the school environment, focusing on digital literacy, citizenship and resilience issues may depend on the specific schools' available resources and allocated funding. Such topics may be taught within the curriculum framework of other subjects rather than as an individual subject. For example, in the UK certain digital literacies are "embedded" in different parts of the curriculum of ICT (Information and Communication Technologies) or PSHE (Personal, Social, Health and Economic Education) or as part of Humanities and Science subjects (Jones, 2018).

In the home environment parents may be worried more about the negative effects of online connectivity than the opportunities it creates for creativity, identity formation and socialisation. However, as the preliminary ice-breaking activities of this study illustrated, children expressed predominantly positive feelings about their engagement with the online environment on the basis of its affordances for enabling them to be sociable, creative, communicative, playful, smart and happy. The positive dimensions of children's online connectivity may not always be evident to parents. Ofcom in the UK has conducted research with parents and children for a number of years, reporting on changes in media access and use of young people and studying how media habits and attitudes change over time. The latest 2019 report, has highlighted that half of ten-year-olds own their own smartphone, that newer platforms such as TikTok and Twitch are gaining popularity, while more children are exposed to violent and "hateful online content" and with most taking no action. At the same time parents are increasingly concerned about children's exposure to websites that promote self-harming related content as well as children's online gaming (e.g. ingame spending and game-related bullying). However, more importantly, fewer parents expressed that being online creates more benefits than staying offline, considering mostly the online risks that children may encounter. What is encouraging, however, is that a higher number of parents discuss online safety with their children than in the past (Ofcom, 2019). At the same time, there are new positive phenomena arising with older children, such as the "Greta effect" and online social activism, as children using social 
media not only for entertainment and socialising purposes but also to support particular causes or organisations (Ofcom, 2019).

It is important for parents to keep the lines of communication as open as possible and work together with children to figure out what is appropriate and acceptable in terms of online conduct and connectivity to ensure that their children's safety, privacy and wellbeing are safeguarded. A positive and open dialogue about the problems of online connectivity can create further opportunities for discussion when difficult situations arise. However, children also connect online and engage in diverse positive activities which allow them to develop and showcase their skills, creativity and talent, to build a community of friends around common interests and hobbies, to express their feelings in ways they could not achieve in person (e.g. via sharing a visual expression or a thought) and to find emotional support, learn together with others and be inspired (e.g. while playing and developing new skills) new skills, exploring new interests and hobbies. Therefore, parents' genuine interest in children's activities can further reinforce children's positive use of digital tools and technologies online as well as the opportunities to learn and grow their knowledge, creativity and talent and develop social skills. Mizuko et al. (2009), in an earlier three-year ethnographic investigation into how young people are living and learning with new media in varied settings - at home, in after-school programs, and in online spaces found that young people's everyday practices involving the use of digital media and social media, placed value on "hanging out" online socially together with their friends, "messing around" when exploring information online or creating with media and tools and "geeking out" when they immersed themselves deeper into activities and developed more specialised knowledge on an area of personal interest. This is similar to a metaphor used by Global Kids Online researchers (Livingstone et al., 2019) which is that of a ladder - signifying a progression of online activities children engage in, commencing with the most "attractive and accessible" ones (e.g. simple activities like watching a video or spending time with friends online) and "levelling up" to more complex activities such as online civic engagement or involvement "in a campaign or protest" (UK Council for Internet Safety, 2018); following in that way Vygotsky's "Zone of Proximal Development" (Cole et al., 1978) and scaffolding approach, which conveys that support and encouragement for more advanced digital activities may be necessary to help develop higher level skills. This progression implies a growth in experience, understanding and commitment with the task at hand and a positive engagement with the online world which often draws less attention or is hidden amidst the negative media portrayals of online connectivity and its impact on children's lives, linked to concerns with online safety, risk taking behaviour and screen time.

The UK Council For child Internet safety (UKCCIS) working group has developed a framework "Education for a Connected World" which can be used as a tool for developing teaching and learning activities for children, embracing this scaffolding approach. The framework focuses on eight different strands of online connectivity and describes different levels of skills which highlight what a child should know and what skills they require to develop: (1) Self-image and identity, (2) Online relationships, (3) Online reputation, (4) Online bullying, (5) Managing online information, (6) Health, well-being and lifestyle, (7) Privacy and security, (8) Copyright and ownership.

With a variety of resources and guidance that are now available, schools can develop systematic planning for the delivery of engaging digital literacy, citizenship and resilience classes, aimed at children and their families. Designing and running learning events, identifying, collating and curating useful resources, monitoring emerging developments, trends and research and working together with other schools to promote digital literacy can help to promote and foster the principles of safe, skills-growing and resilient online interactions.
An educational video cartoon series 
JRIT

15,1

\section{References}

Bandura, A. (Ed.), (1971), Psychological Modeling: Conflicting Theories, Aldine-Atherton, New York, NY.

Cole, M., John-Steiner, V., Scribner, S. and Souberman, E. (Eds) (1978), Vygotsky, L. Mind in Society: The Development of Higher Psychological Processes, Cambridge University Press, Cambridge.

Council of Europe [CoE] (2019), "Recommendation CM/Rec (2019)10 of the Committee of Ministers to member States on developing and promoting digital citizenship education", available at: https:// search.coe.int $/ \mathrm{cm} /$ Pages/result_details.aspx?ObjectID $=090000168098 \mathrm{de} 08$ (accessed 10 June 2020).

Council of Europe (2020), "Digital citizenship education", available at: https:/www.coe.int/en/web/ digital-citizenship-education/home?desktop=true (accessed 9 June 2020).

Dalacosta, K., Kamariotaki-Paparrigopoulou, M., Palyvos, J.A. and Spyrellis, N. (2009), "Multimedia application with animated cartoons for teaching science in elementary education", Computers and Education, Vol. 52, pp. 741-748.

Department for Digital, Culture, Media and Sport (2020), "Closed consultation. Online harms white paper - initial consultation response", 12 February 2020, available at https:/www.gov.uk/ government/consultations/online-harms-white-paper/public-feedback/online-harms-whitepaper-initial-consultation-response (accessed 10 June 2020).

d'Haenens, L., Vandoninck, S. and Donoso, V. (2013), “How to cope and build online resilience?”, EU Kinds Online, available at: http://www.lse.ac.uk/media@1se/research/EUKidsOnline/EU\% 20Kids\%20III/Reports/Copingonlineresilience.pdf (accessed 10 June 2020).

Feinberg, T. and Robey, N. (2010), Cyberbullying: Intervention and Prevention Strategies. Helping Children at Home and School III, National Association of School Psychologists, Vol. 38, pp. 1-5, available at: $\mathrm{http} / / \mathrm{www}$.centerforchildwelfare.org/kb/parenting/Cyberbullying-Intervention $\%$ 20 and \%20Prevention\%20Strategies.pdf (accessed 2 December 2020).

IFLA The International Federation of Library Associations and Institutions (2020), "How to spot fake news", available at: https://www.ifla.org/publications/node/11174 (accessed 10 June 2020).

Jones, R. (2018), “Schools. Where does information literacy fit within the schools sector?' CILIP information literacy group", available at: https://infolit.org.uk/sectors/schools/ (accessed 10 June 2020).

Liu, C. and Elms, P. (2019), "Animating student engagement: the impacts of cartoon instructional videos on learning experience”, Research in Learning Technology, Vol. 2, doi: 10.25304/rlt.v27. 2124 (accessed 10 June 2020).

Livingstone, S., Kardefelt Winther, D., Kanchev, P., Cabello, P., Claro, M., Burton, P. and Phyfer, J. (2019), Is there a Ladder of Children's Online Participation? Findings from Three Global Kids Online Countries, Innocenti Research Briefs no. 2019-02, UNICEF Office of Research Innocenti, Florence.

Martzoukou, K. (2019), "Digital competencies for digital citizenship of pre-teen children: some reflections for librarians", LILAC 2019. University of Nottingham 24-26 April 2019, available at: https://www.slideshare.net/infolit_group/digital-competencies-for-digital-citizenship-of-preteenchildren-martzoukou (accessed 10 June 2020).

Martzoukou, K. and Geekie, J. (2019), “Celebrating UNESCO MIL week 2019: case studies using the information literacy group (ILG) definition of information literacy and exploring children's information and digital literacy issues", 24th October 2019, available at: https:/www. slideshare.net/martzoukou/cilip-ilg-talk-unesco-mil-week-24th-october-2019 (accessed 10 June 2020).

McGrew, S., Breakstone, J., Ortega, T., Smith, M. and Wineburg, S. (2018), "Can students evaluate online sources? Learning from assessments of civic online reasoning", Theory and Research in Social Education, Vol. 46 No. 2, pp. 165-193.

Mizuko, I., Baumer, S., Bittanti, M., Boyd, D., Cody, R., Herr Stephenson, B., Horst, H.A., Lange, P.G., Mahendran, D., Martínez, K.Z., Pascoe, C.J., Perkel, D., Robinson, L., Sims, C. and Tripp, L. 
(2009), Hanging Out, Messing Around, and Geeking Out: Kids Living and Learning with New Media, MIT Press, Cambridge, MA.

National Literacy Trust (2018), "Fake news and critical literacy: the final report of the commission on fake news and the teaching of critical literacy in schools", available at: https://cdn.literacytrust. org.uk/media/documents/Fake_news_and_critical_literacy_-_final_report.pdf (accessed 10 June 2020).

Ofcom (2019), "Children and parents: media use and attitudes report 2018", available at: https://www. ofcom.org.uk/_data/assets/pdf_file/0024/134907/children-and-parents-media-use-and-attitudes2018.pdf (accessed 10 June 2020).

Ofcom (2020), "Covid-19 news and information: 12-15 year old children's news consumption and attitudes", available at: https://www.ofcom.org.uk/_data/assets/pdf_file/0027/195345/covid-19news-consumption-children-12-15-report.pdf (accessed 10 June 2020).

Özer, D. and Avc1, I.B. (2015), "Cartoons as educational Tools and the presentation of cultural differences via cartoons", Procedia - Social and Behavioral Sciences, Vol. 191, pp. 418-423.

Picton, I. and Teravainen, A. (2017), Fake News and Critical Literacy: An Evidence Review, The National Literacy Trust, London.

Plotagon (2019), "Plotagon showcase: gamification, storytelling and scenario-based learning with plotagon Studio", available at: https://www.plotagon.com/cases/ (accessed 10 June 2020).

Reynolds, 1. and Scott, R. (2016), There is an Urgent Need for Schools to Develop Digital Citizenship in Our Young People: Digital Citizens: Countering Extremism Online, DEMOS, London, available at: https://www.demos.co.uk/wp-content/uploads/2016/12/Digital-Citizenship-web.pdf (accessed 10 June 2020).

Salmons, H. (2016), "Research: teenage use of mobile devices during the night", HMC The Headmasters' and Headmistresses' Conference, 6th October 2016, available at: https://www.hmc. org.uk/blog/research-teenage-use-mobile-devices-night/ (accessed 10 December 2020).

The Children's Society and Young Minds (2018a), "Safety Net: Cyberbullying's impact on young people's mental health: inquiry report summary", available at: https://youngminds.org.uk/ media/2190/pcr144a_social_media_cyberbullying_inquiry_summary_report.pdf (accessed 2 December 2020).

The Children's Society and Young Minds (2018b), "Safety Net: cyberbullying's impact on young people's mental health Inquiry report", available at: https:/www.alexchalk.com/sites/www. alexchalk.com/files/201804/pcr144b_social_media_cyberbullying_inquiry_full_report.pdf (accessed 10 June 2020).

Türkmen, N. (2012), "Role of cartoons to transfer of culture and pepee", Cumhuriyet University, Journal of Social Sciences, Vol. 36 No. 2, pp. 707-719.

UK Council for Internet Safety (2018), "Education for a connected world", available at: https:// www.gov.uk/government/publications/education-for-a-connected-world (accessed 10 June 2020).

UK Council for Internet Safety (2020), "Digital resilience framework", available at: https://assets. publishing.service.gov.uk/government/uploads/system/uploads/attachment_data/file/831217/ UKCIS_Digital_Resilience_Framework.pdf (accessed 10 June 2020).

Wyk, V. and Micheal, M. (2011), "The use of cartoons as a teaching tool to enhance student learning in economics education", Journal of Social Science, Vol. 26 No. 2, pp. 117-130.

\section{Further reading}

Chartered Institute of Library and Information Professionals in Scotland (2019), "Maddie is Online': teaching information literacy and digital skills to schoolchildren via animation", available at: https://www.cilips.org.uk/maddie-is-online-teaching-information-literacy-and-digital-skills-toschoolchildren-via-animation/ (accessed 10 June 2020).
An educational video cartoon series 
JRIT

15,1

82
Copyright Licensing Agency (2019), "Teaching the digital citizens of tomorrow", available at: https:// cla.co.uk/blog/schools/maddie-is-online (accessed 10 June 2020).

Cortesi, S.C., Hasse, A., Lombana-Bermudez, A., Kim, S. and Gasser, U., (2020), "Youth and digital Citizenship+ (plus): understanding skills for a digital world” (March 20, 2020). Berkman Klein Center Research Publication No. 2020-2, available at: https://ssrn.com/abstract $=3557518$ or http://dx.doi.org/10.2139/ssrn.3557518 (accessed June 10, 2020).

\section{Corresponding author}

Konstantina Martzoukou can be contacted at: k.martzoukou@rgu.ac.uk

For instructions on how to order reprints of this article, please visit our website: 